\title{
Activation of P2X7 receptor and NLRP3 inflammasome assembly in hippocampal glial cells mediates chronic stress-induced depressive-like behaviors
}

Na Yue ${ }^{1 \dagger}$, Huijie Huang ${ }^{1 \dagger}$, Xiaocang Zhu', Qiuqin Han ${ }^{1}$, Yalin Wang ${ }^{1}$, Bing Li ${ }^{1}$, Qiong Liu ${ }^{2,3}$, Gencheng Wu', Yuqiu Zhang ${ }^{1 *}$ and Jin $\mathrm{Yu}^{1 *}$ (D)

\begin{abstract}

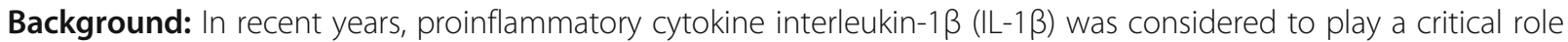
in the pathogenesis of depression. In addition, P2X7 receptor (P2X7R), a member of the purinergic receptor family, which is predominantly present on microglia, as well as on astrocytes and neurons in lesser amounts in the central nervous system, was suggested to be involved in the processing and releasing of IL-1 3 . Here, we investigated the role of P2X7R in the pathogenesis of depression.
\end{abstract}

Methods: Male Sprague-Dawley rats were subjected to chronic unpredictable stressors (CUS) for 3 weeks. At the end of week 1, 2, and 3, extracellular ATP, caspase 1, IL-1 $\beta$, and components and activation of NLRP3 inflammasome (nucleotide-binding, leucine-rich repeat, pyrin domain containing 3) were evaluated as biomarker of neuroinflammation. In separate experiments, the rats were microinjected with P2X7R agonists ATP, BzATP, and saline into the hippocampus, respectively, or exposed to CUS combined with hippocampal microinjection with P2X7R antagonist, BBG and A438079, and saline, respectively, for 3 weeks, followed by exposed to forced swimming test and open-field test. Moreover, we also evaluated the depressive and anxiety-like behavior of P2X7-null mice in forced swimming test, open-field test, and elevated plus maze.

Results: Along with stress accumulation, extracellular ATP, cleaved-caspase 1, IL-1 $\beta$, and ASC were significantly enhanced in the hippocampus, but P2X7R and NLRP3 were not. Immunoprecipitation assay indicated that along with the accumulation of stress, assembly of NLRP3 inflammasome and cleaved caspase 1 in NLRP3 inflammasome were significantly increased. Moreover, antagonists of P2X7R, either BBG or A438079, prevented the development of depressive-like behaviors induced by chronic unpredictable stress in rats. Meanwhile, we could not observe any depressive-like or anxiety-like behaviors of P2X7-null mice after they had been exposed to CUS. The results implied that P2X7 knockout could impede the development of depressive-like and anxiety-like behaviors induced by CUS. In contrast, chronic administration of agonists of P2X7R, either ATP or BZATP, could induce depressive-like behaviors.

Conclusions: The activation of P2X7R and subsequent NLRP3 inflammasome in hippocampal microglial cells could mediate depressive-like behaviors, which suggests a new therapeutic target for the prevention and treatment of depression.

Keywords: Depression, P2X7 receptor, eATP, Glia, NLRP3 inflammasome

\footnotetext{
* Correspondence: yuqiuzhang@fudan.edu.cn; yujin@shmu.edu.cn

${ }^{\dagger}$ Equal contributors

'Department of Integrative Medicine and Neurobiology, School of Basic

Medical Sciences, Institues of Brain Science, State Key Laboratory of Medical

Neurobiology and Collaborative Innovation Center for Brain Science, Fudan

University, Shanghai 200032, China

Full list of author information is available at the end of the article
} 


\section{Background}

Depression is a common mental disease associated with long-term morbidity, a high recurrence rate, and significant mortality [1]. It is now clear that chronic uncontrollable stress is the main cause for this disorder [2-4]; underlying mechanisms of stress or depression have not been fully elucidated. In the past decade, neuroinflammation, described by overproduction of inflammatory cytokines in the brain, has been recognized as an important mechanism of depression [5-7]. Depressed patients exhibited increased inflammatory cytokines, such as IL- $1 \beta$, IL-6, and IFN- $\gamma$, in peripheral circulation and some brain regions [8-10]. Animal studies also demonstrate that exposure to stress increases IL- $1 \beta$ in several brain areas, including the hippocampus, a key area of the brain responsible for memory and emotion. [11-13]. Central administration of IL-1 $\beta$ produces several stress-like effects and pathological changes [12, 14-16]. Hippocampal tissue inflammation and, particularly, enhanced interleukin-1 $\beta$ (IL-1 $\beta$ ) signaling may contribute to depression [17]. In contrast, blockade of the hippocampal IL-1 $\beta$ receptor, IL-1RI, abolishes the anhedonic behavioral effects of chronic unpredictable stress (CUS) [18, 19]. However, the mechanisms underlying the ability of stress to increase IL-1 $\beta$ and inflammatory responses in the hippocampus have not been determined.

Meanwhile, the role of ATP-gated transmembrane cation channel P2X7 receptor in the neuroinflammation has received particular attention due to its widespread involvement as a key regulatory element of IL-1 $\beta$ maturation [20-22]. It has been reported that in the brain, $\mathrm{P} 2 \mathrm{X} 7 \mathrm{R}$ is an ionotropic receptor located predominantly on microglia and is activated in response to cellular danger signals, such as ATP [23]. In contrast, P2X7R antagonists inhibited IL-1 $\beta$ release from glial cells [24]. Furthermore, the $P 2 X 7 R$ gene which is located on chromosome 12q24.31 has been identified as a susceptibility locus for affective disorders [25]. And recent studies have exhibited that P2X7R knockout may have an antidepressant-like effect in mice [26-28]. The emerging evidence indicates that P2X7R maybe plays a pivotal role in depression and mediates the IL- $1 \beta$ maturation, but the precise mechanisms associated with stress-induced hippocampal neuroinflammation merited further investigation.

Studies of peripheral immune cells demonstrated that activation of P2X7R induced oligomerization of NLRP3 with an adaptor protein (ASC [apoptosis-associated speck-like protein containing a CARD]) and pro-caspase$1[29,30]$. The multiprotein complex named the inflammasome cleaves pro-caspase- 1 to mature caspase-1, which subsequently causes the maturation of pro-IL-1 $\beta[31,32]$. In addition, recently, researches exhibited that NLRP3 inflammasome is activated in depressed animal models
[33] and in depressive patients as well [34], which suggests that NLRP3 inflammasome might be a new target and offer new perspectives in the study of depression [34].

Moving from this evidence, the aim of the present investigation was to identify the pathways by which chronic stress increases IL-1 $\beta$ and the resulting depressive-like behaviors. We exhibited that with the accumulation of stressors, the concentration of eATP increased significantly. Meanwhile, the accumulation of stressors caused an increase in the assembly of NLRP3 inflammasome, a prominent downstream signal of P2X7R. Besides, the protein levels of ASC and cleavedcaspase 1 (p10), a component and product of NLRP3 inflammasome respectively, were increased after exposure to CUS. Also, the level of hippocampal IL-1 $\beta$ (p17), product of active caspase $1(\mathrm{p} 10)$, were upregulated with the accumulation of stressors.

\section{Methods \\ Animals}

Male Sprague-Dawley rats (180-200 g) and wild-type C57BL/6 and P2X7-null mice (male and female, 25$30 \mathrm{~g})$ were housed in groups of $2-4$ per cage under a 12-h light/dark cycle with ad libitum to access to food and water (except when indicated). Eight to 12 rats or mice per group were randomly chosen. The maintenance of rat and mouse colonies and all animal treatments and procedures were in accordance with NIH laboratory care standards and approved by the Experimental Animal Ethics Committee of Shanghai Medical College, Fudan University.

\section{CUS procedure}

CUS is a rodent model of depression which animals are exposed to random sequence of mild stressors as previously described [35]. Rats were subjected to 6 different stressors: water deprivation $(40 \mathrm{~h})$, food deprivation (40 h), light-dark cycle reversal, hot environment $\left(40{ }^{\circ} \mathrm{C}\right.$, $5 \mathrm{~min})$, swimming in cold water $\left(4^{\circ} \mathrm{C}, 5 \mathrm{~min}\right)$, and cage shake $(30 \mathrm{~min})$. These stressors were performed every per day in a random order for 1,2 , and 3 weeks in different experiments (see Table 1). Mice were subjected to nine different stressors: food and water deprivation $(24 \mathrm{~h})$, light inversion $(12 \mathrm{~h})$, stroboscopic $(12 \mathrm{~h})$, hot environment $\left(40{ }^{\circ} \mathrm{C}, 5 \mathrm{~min}\right)$, swimming in cold water $\left(4{ }^{\circ} \mathrm{C}, 5 \mathrm{~min}\right)$, cage shake $(30 \mathrm{~min})$, wet bedding $(6 \mathrm{~h})$, cage tilt $(2 \mathrm{~h})$, and restraint $(2 \mathrm{~h})$. These stressors were performed two per day in a random order for 5 weeks (see Table 2).

\section{Behavioral testing}

Open-field test were performed as described before [36], rats or mice were placed into the center of a Plexiglas 
Table 1 CUS procedure for rats

\begin{tabular}{|c|c|c|c|c|c|c|c|}
\hline Week & Monday & Tuesday & Wednesday & Thursday & Friday & Saturday & Sunday \\
\hline 1 & $\begin{array}{l}\text { Hot environment } \\
40^{\circ} \mathrm{C}, 5 \text { min }\end{array}$ & $\begin{array}{l}\text { Water deprivation } \\
24 \mathrm{~h}\end{array}$ & $\begin{array}{l}\text { Swimming in cold } \\
\text { water } 5 \mathrm{~min}\end{array}$ & $\begin{array}{l}\text { Cage shake } \\
30 \mathrm{~min}\end{array}$ & $\begin{array}{l}\text { Light-dark } \\
\text { cycle reversal }\end{array}$ & $\begin{array}{l}\text { Hot environment } \\
40^{\circ} \mathrm{C}, 5 \mathrm{~min}\end{array}$ & Food deprivation \\
\hline 2 & $\begin{array}{l}\text { Swimming in cold } \\
\text { water } 5 \mathrm{~min}\end{array}$ & $\begin{array}{l}\text { Light-dark cycle } \\
\text { reversal }\end{array}$ & $\begin{array}{l}\text { Hot environment } \\
40^{\circ} \mathrm{C}, 5 \mathrm{~min}\end{array}$ & $\begin{array}{l}\text { Water deprivation } \\
24 \mathrm{~h}\end{array}$ & $\begin{array}{l}\text { Cage shake } \\
30 \mathrm{~min}\end{array}$ & $\begin{array}{l}\text { Cage tilt } 2 \mathrm{~h} \text { Food } \\
\text { deprivation } 24 \mathrm{~h}\end{array}$ & $\begin{array}{l}\text { Swimming in cold } \\
\text { water } 5 \text { min }\end{array}$ \\
\hline 3 & $\begin{array}{l}\text { Cage shake } \\
30 \mathrm{~min}\end{array}$ & $\begin{array}{l}\text { Hot environment } \\
40^{\circ} \mathrm{C}, 5 \mathrm{~min}\end{array}$ & $\begin{array}{l}\text { Food deprivation } \\
24 \mathrm{~h}\end{array}$ & $\begin{array}{l}\text { Light-dark } \\
\text { cycle reversal }\end{array}$ & $\begin{array}{l}\text { Water deprivation } \\
24 \mathrm{~h}\end{array}$ & $\begin{array}{l}\text { Swimming in cold } \\
\text { water } 5 \text { min }\end{array}$ & $\begin{array}{l}\text { Hot environment } \\
40^{\circ} \mathrm{C}, 5 \mathrm{~min}\end{array}$ \\
\hline
\end{tabular}

box (rats: $100 \mathrm{~cm} \times 100 \mathrm{~cm} \times 40 \mathrm{~cm}$, mice: $50 \mathrm{~cm} \times$ $50 \mathrm{~cm} \times 40 \mathrm{~cm}$, respectively) in a brightly lit room. During a 5-min session, animals were scored for the number of rearing and the distance traveled in the box. Animal behavior was recorded and subsequently analyzed using a video-tracking system (Shanghai Mobile Datum Information Technology Company, Shanghai, China).

For the forced swimming test, rats or mice were individually put into 18 - or 15 -cm-diameter glass cylinder filled to 30 or $20 \mathrm{~cm}$ with $23 \pm 1{ }^{\circ} \mathrm{C}$ water, respectively, as we described before [37]. During analysis of the recordings, immobility was defined as the absence of all movement except motions required maintaining the animal's head above the water. Struggling was defined as vigorous movements with forepaws breaking the water. Results were expressed as time (in seconds) that animals spent immobile or struggling during a 5-min session.

The elevated plus maze was shaped like a plus sign and consisted of a central platform $(5 \times 5 \mathrm{~cm})$, two opposite open arms $(30 \mathrm{~cm} \times 5 \mathrm{~cm})$, and two equal-sized opposite closed arms, elevated $50 \mathrm{~cm}$ from floor and illuminated by a dim light. Individual trials lasted for $5 \mathrm{~min}$ each and were recorded with a video-tracking system (Shanghai Mobile Datum Information Technology Company, Shanghai, China). Percentage of open-arm entries ([open entries] $/[$ total entries $] \times 100)$ and open-arm time ([time in open arms]/[time in total arms] $\times 100$ ) were calculated as we described in our previous paper [38].

All the behavioral tests were performed by an individual who was blinded to the animal's treatment status.

\section{Stereotaxic microinjection}

The rats were anesthetized with pentobarbital sodium and placed in a stereotaxic frame. A brain infusion cannula was bilaterally implanted in the hippocampus (AP $\left.=-3.8, \mathrm{ML}= \pm 3 \mathrm{~mm}, \mathrm{DV}=3.5 \mathrm{~mm}, 1 \mu \mathrm{l}, 0.5 \mu \mathrm{l} \mathrm{min}{ }^{-1}\right)$. Seven days after implantation, vehicle, ATP (100 nM), BzATP (10.5 nM), BBG (Brilliant Blue G, one of the safest dyes currently used, is a well-known P2X7 receptor antagonist,1 pM), or A438079 (a selective competitive antagonist for the human and rodent $\mathrm{P} 2 \mathrm{X} 7$ receptor with good bioavailability and CNS penetration widely used in animal models of disease, $1.75 \mathrm{nM}$ ) was delivered into the hippocampus of free-moving rats for 21 days [39-49]. The behavioral test was conducted before the infusion on the first day and $30 \mathrm{~min}$ following the infusion on the 21th day. All compounds were dissolved in ACSF.

\section{Experimental procedures}

Before starting every behavioral or pharmacological experiment, the mice or rats were randomly assigned to receive different treatments.

\section{Experiment 1: change of eATP, P2X7R, NLRP3 inflammasome, astrocyte, and microglia in the hippocampus of rats submitted to CUS}

Rats were exposed to one stressor every day for 1, 2, or 3 weeks. The stressors were used in a random order as mentioned above. Twenty-four hours after the last stressor, five rats of every group were randomly selected to be stereotaxically implanted with a microdialysis intracerebral guide cannula into the hippocampal DG zone. The hippocampal microdialysates were later collected through the cannula from the rats. The operational details were described below. Other rats of every group were immediately sacrificed to collect the brain tissue. Control animals were exposed to behavioral tests and not subjected to any stressors.

\section{Experiment 2: effect of antagonists of $P 2 X 7 R$ in model animals}

Following exposure to the stressor of CUS $30 \mathrm{~min}$ later, the rats were microinjected with BBG (1 pM, Sigma/Aldrich, $n=11$ ), A438079 (1.75 nM, Sigma/Aldrich, $n=13)$, and vehicle $(n=11)$, respectively, in the hippocampus every day for 3 weeks. Twenty-four hours after the last stressor, the rats were assessed for depressive-like behaviors in open-field test (OFT) and forced swimming test (FST).

Experiment 3: effect of agonists of P2X7R in normal animals Rats received ATP (100 nM, Sigma/Aldrich, $n=12)$, BzATP (10.5 nM, Sigma/Aldrich, $n=12)$, vehicle $(n=$ 12 ), or CUS treatment, respectively, for 3 weeks. All of the drugs were microinjected into the hippocampus once a day. The rats in the CUS group were exposed to one stressor in a random order every day. Twenty-four 


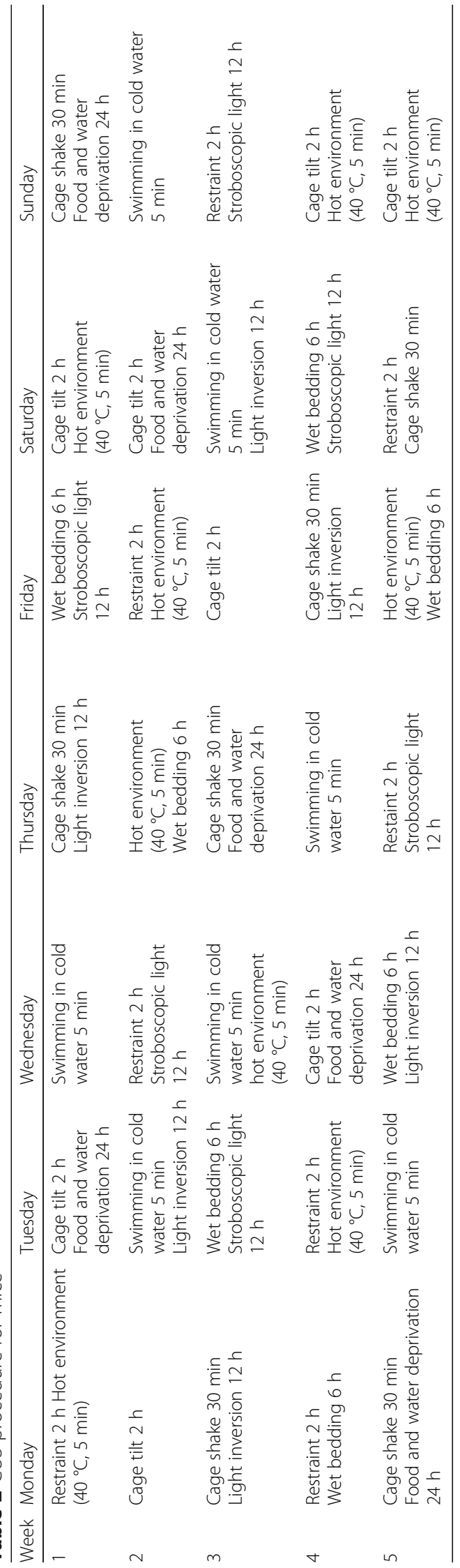


hours after the last stressor, the rats were assessed for depressive-like behaviors in OFT and FST.

\section{Experiment 4: effect of CUS in P2X7-null mice}

Wild-type C57BL/6 and P2X7-null mice (male and female) were exposed to a variety of stressors for 5 weeks. The stressors were used in a random order, as mentioned above. Twenty-four hours after the end of the CUS protocol, the mice were assessed for depressive-like behaviors in OFT, FST, and elevated plus maze test (EPM). Control animals were exposed to behavioral tests and not subjected to any stressors.

\section{Measurement of eATP concentration in the hippocampus} The microdialysis-intracerebral-guide cannula (Bioanalytical Systems, Inc., West Lafayette, USA) was implanted into the hippocampal DG zone (V $3.5 \mathrm{~mm}$, AP $3.8 \mathrm{~mm}$, ML 3.0). A microdialysis probe with a 2-mm membrane (Bioanalytical Systems, Inc., WestLafayette, USA) was then placed through the guide cannula into the DG region. Artificial cerebrospinal fluid (ACSF) with the ectonucleotidase inhibitor 6 - $N, N$-diethyl- $\beta$ - $\gamma$-dibromomethylene-D-adenosine-5-triphosphate FPL 67156 (ARL 67156 trisodium salt) was applied as the perfusate. The optimal perfusion flow-rate was set at $1 \mu \mathrm{l} / \mathrm{min}$, and the sampling time for each rat was $2.5 \mathrm{~h}, 30 \mathrm{~min}$ after exposuring to the stressor of CUS. The ATP levels were determined using a bioluminescent ATP assay kit (Promega, Madison, WI, USA) and a luminometer (PerkinElmer) according to the manufacturer's instructions. A calibration curve was obtained from standard ATP samples, and the luminescence of normal medium was considered to be the background ATP level.

\section{Immunohistochemical analysis}

The brains were separated and post fixed in 4\% PFA at $4{ }^{\circ} \mathrm{C}$ overnight and immersed in $20 \%$ sucrose (4\% PFA as solvent) followed by $30 \%$ sucrose (in $0.1 \mathrm{M} \mathrm{PBS}$ ). The brain samples were cut into 30- $\mu$ m-thick sections (CM1850, Leica Microsystems, Wetzlar, Germany). Sections were incubated in $0.01 \mathrm{~mol} / \mathrm{L}$ citrate buffer, $\mathrm{pH} 6.0$ for high-temperature antigen retrieval. Tissues were blocked in 2\% (wt/vol) BSA (Sigma) and then exposed overnight to the following primary antibody mixtures: anti-P2X7R (Abcam, 1:400), anti-GFAP (Thermo, 1:1000), or anti-Iba-1 (Wako, 1:1000) at $4{ }^{\circ} \mathrm{C}$. Detection of primary antibodies was performed with secondary antibodies (donkey-anti-mouse, Alexa 594 conjugated,1:1000, Invitrogen, USA; donkey anti rabbit, Alexa 594 conjugated, 1:1000, Invitrogen, USA; Hoechst, 1: 1000, Beyotime, China) for $1 \mathrm{~h}$ in the dark. The sections were then washed five times with PBS in the dark. Immunofluorescent sections were observed with a Leica SP5 fluorescence microscope, using excitation wavelengths of $633 \mathrm{~nm}$ (helium/neon2, blue Cy5-labelling), $543 \mathrm{~nm}$ (helium/neon1, red Cy3-immunofluorescence), and $488 \mathrm{~nm}$ (argon, yellow-green Cy2-immunofluorescence), and images were captured with a CCD spot camera for data analysis. Three regions per hippocampus section and three sections per animal were counted by experimenters who were blind to the experiment design.

\section{Western blot analysis}

The hippocampi of rats were homogenized in RIPA buffer (Thermo Scientific) with protease inhibitors (Beyotime). Protein samples were run on $12 \%$ trisglycine SDS-PAGE gels, transferred to PVDF membrane $(0.2$ or $0.45 \mu \mathrm{m})$, and blotted with antibodies against P2X7R (1:200, Santa Cruz); Cryopyrin (NLRP3, 1:200, Santa Cruz); Caspase-1 (1:200, Santa Cruz); ASC (1:200, Santa Cruz); IL-1 $\beta$ (1: 1000, R\&D System); or GAPDH (1:10000, KangCheng). Primary antibody incubation was performed overnight at $4{ }^{\circ} \mathrm{C}$. Secondary antibodies (1:10000, Earthox) were incubated for $1 \mathrm{~h}$ at room temperature. The signal was captured on an ImageQuant LAS4000 mini image analyzer (GE Healthcare, Buckinghamshire, UK), and the band levels were quantified using Image J software (NIH, Bethesda, MD, USA).

\section{Quantitative real-time RT-PCR}

Total RNA was isolated from hippocampi of rats using TRIzol reagent (Invitrogen) according to the manufacturer's instructions. cDNA was synthesized by a PrimeScript Kit (Bio-Rad). Quantitative real-time PCR was performed by using gene-specific primers and SYBR Premix Ex Taq (Bio-Rad, California, USA). Oligonucleotide primers specific for rat are GFAP (F 5'GAGATGATGG AGCTCAATGACC 3'; R 5'TGGATCTCCTCCTCC AGCGA 3'); Iba-1 (F 5' GGGATCAACAAGCACTTC 3'; R 5' TATCTCCATTGCCATTCA3'); GAPDH (F 5' CCCTTCATTGACCTCAACTAC 3'; R 5' CTTCTCCA TGGTGGTGAAGAC 3'). Relative mRNA expression levels were analyzed using the formula $2^{-\Delta \Delta C t}$ method and normalized to the GAPDH ribosomal RNA.

\section{Immunoprecipitation (IP)}

This test was performed as we described in our previous paper [50]. Hippocampus lysates $(500 \mu \mathrm{g})$ were immunoprecipitated with $1 \mu \mathrm{g}$ of anti-ASC antibody (Santa Cruz) overnight at $4{ }^{\circ} \mathrm{C}$, then incubated with $30 \mu \mathrm{l}$ of protein A agarose beads (Cell Signaling) at $4{ }^{\circ} \mathrm{C}$ for $4 \mathrm{~h}$, and centrifuged at $12,000 \times g$ for $60 \mathrm{~s}$. Protein complexes were washed five times with RIPA buffer, resuspended in $2 \times$ loading buffer, and heated at $95{ }^{\circ} \mathrm{C}$ for $10 \mathrm{~min}$ before western blot analysis by using the following antibodies: rabbit anti-ASC (1:1000, Santa Cruz), rabbit anti-NALP1 (1:200: Abcam), rabbit anti-NLRP3 (1:200, Santa Cruz), and rabbit anti-caspase-1 (1:200: 
Santa Cruz). Whole tissue lysate prepared for IP $(50 \mu \mathrm{g})$ was used as an input, and homophytic IgG as the negative control.

\section{Statistical analysis}

All data were analyzed using SPSS 16.0 (SPSS Inc., Chicago, USA). The data collection and analysis were performed independently by two experimenters. Results are expressed as the mean \pm standard error. Data were analyzed using one- or two-way analysis of variance (ANOVA) according to the factors introduced in the experimental design. Where $\mathrm{F}$ ratios were significant, post hoc comparisons were made using the Tukey post hoc test. Significance levels were set at $p<0.05$.

\section{Results}

CUS causes extracellular ATP increment in the hippocampus in early stage

We first detected the expression of P2X7R in normal rats' hippocampus. The results showed that P2X7R were predominantly expressed by microglia, as well as astrocyte in less amounts (Fig.1a, Additional file 1: Figure S1 A-I). The next question is whether CUS causes eATP, the endogenous ligand of P2X7R to increase or induce the change of P2X7R in the hippocampus of rats. Thereby, we further detected the concentration of eATP and the expression of P2X7R in the rats' hippocampus after they were exposed to 1,2 , and 3 weeks of CUS, respectively. As shown in Fig.1b, compared to the normal rats, the stressed rats showed a noteworthy
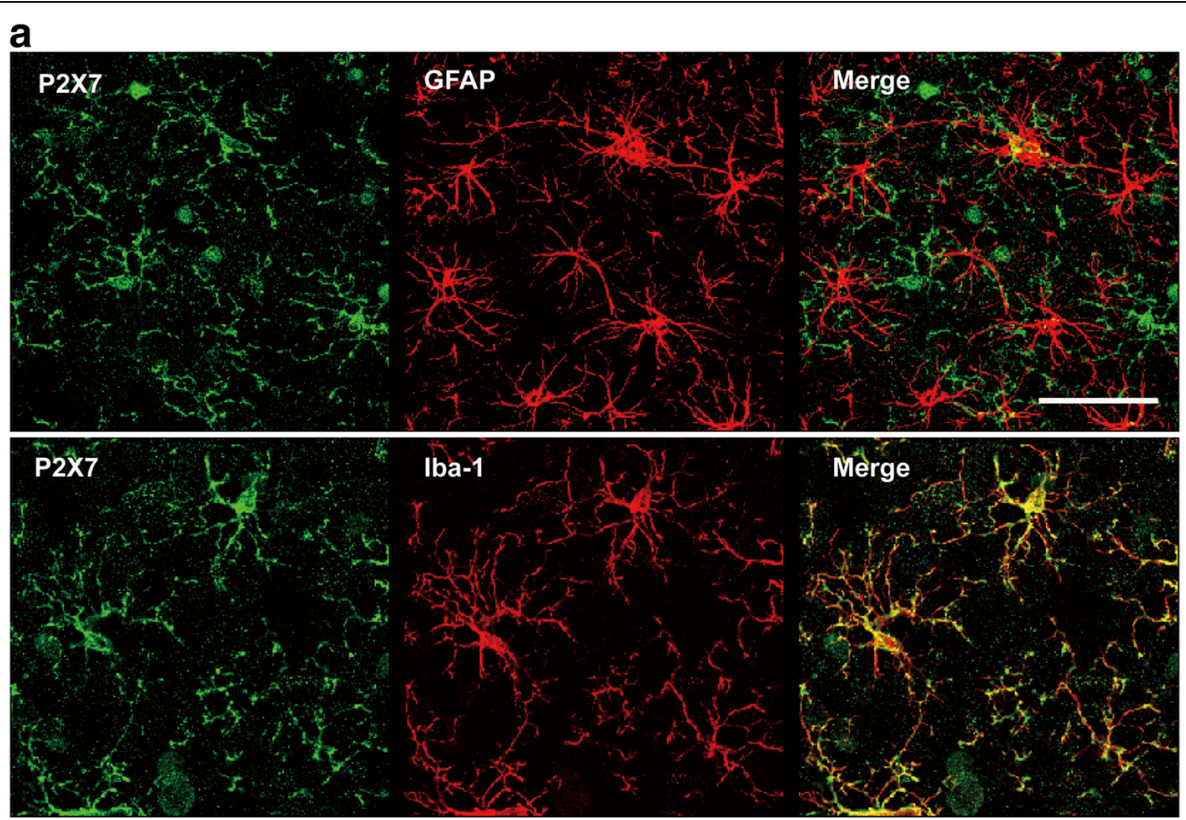

b

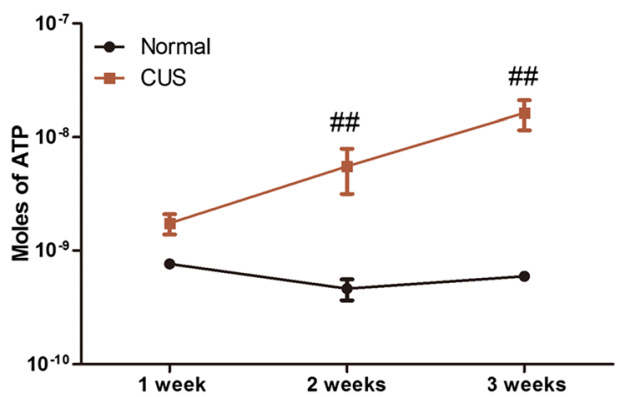

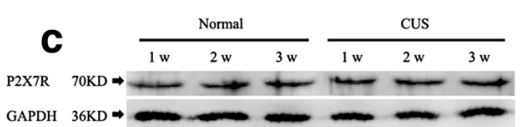

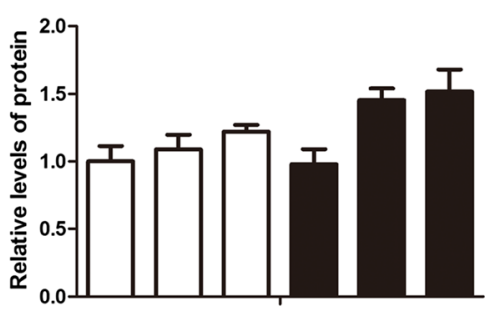

Fig. 1 CUS increases ATP in microdialysates from the hippocampus but not levels of P2X7 receptor protein in the hippocampus. a Immunofluorescence staining of hippocampal sections from normal rats. P2X7R (green), Iba-1 (red), GFAP (red), DAPI (blue); scale bar, 50 um. b Microdialysis samples were collected from the hippocampus of rats exposed to 1, 2, and 3 weeks of CUS, respectively, and analyzed for levels of ATP ( $n=4$ per group). c Western blots of P2X7R in the hippocampus from rats exposed to 1, 2, and 3 weeks of CUS, respectively. GAPDH was used as a loading control and the graphs represent the mean \pm SEM ( $n=4$ per group). ${ }^{\#} p<0.01$ compared to normal rats at the same time point 
increase in concentration of eATP in the hippocampus from the first weekend to the third weekend after being exposed to the CUS procedure. Meanwhile, we could not detect any difference in protein levels of P2X7R in the hippocampus between different groups (Fig. 1c).

\section{CUS causes the cleavage of caspase- 1}

As we know, P2X7R activation by ATP stimulates caspase-1 activity which, in turn, leads to the regulated release of the cytokine interleukin-1 (IL-1 $\beta$ ) from phagocytes [51]. We further investigated whether CUS can also cause cleavage of caspase- 1 and consequent matured IL-1 $\beta$ increase along with the eATP augment. We found that matured IL- $1 \beta$ was slightly enhanced in the hippocampus of rats after exposed to 1, 2, and 3 weeks of CUS, respectively (Fig. 2a, b). Additionally, 1, 2 , and 3 weeks of CUS significantly increased the protein level of caspase-1 p10 (cleaved-caspase-1) but not caspase-1 p45 (Fig. 2c, d) in the hippocampus of rats. These results suggest that stress induced capspase-1 activation and interleukin-1 maturation in the hippocampus of rats.

\section{CUS also induces NLRP3 inflammasome assembly in the hippocampus}

Many research studies have indicated that the assembly of inflammasome is the key pathway to activating caspase-1 [30, 32]. The inflammasome is a multiprotein complex, which was formed by NOD-like receptors' (NLRs) family members, adaptor ASC (apoptosis-associated speck-like protein containing a CARD) and procaspase-1. Among NLRs, NLRP3 inflammasome were found to be activated or highly expressed in glial cells following brain injury or in several neurodegenerative diseases [52-55]. Besides, one of the most potent activators of the NLRP3 inflammasome is extracellular ATP acting at the P2X7 receptor (P2X7R) [29]. Therefore, we further detected the NLRP3 and ASC protein levels and the assembly of NLRP3 inflammasome in the hippocampus. We found that CUS could significantly increase the expression of ASC, but not NLRP3 protein level in the hippocampus (Fig. 3a, b). Moreover, we detected NLRP3, caspase- 1 , and the active p10 caspase- 1 in the immunoprecipitated products of an ASC antibody (Fig.3c). And the subsequent western blot results showed that along with stress accumulation, the NLRP3 and cleaved caspase- 1 in the IP product of an ASC antibody were significantly increased (Fig. $3 c-e$ ). The results demonstrate that the CUS promoted the assembly of NLRP3, ASC, and caspase- 1 and the activation of caspase- 1 .

\section{Antagonist of P2X7R could impede the creation of depressive-like behavior induced by CUS}

To further clarify the role of P2X7 receptor in depressivelike behaviors, we investigated if P2X7R blockade could impede the formulation of depressive-like behaviors. For

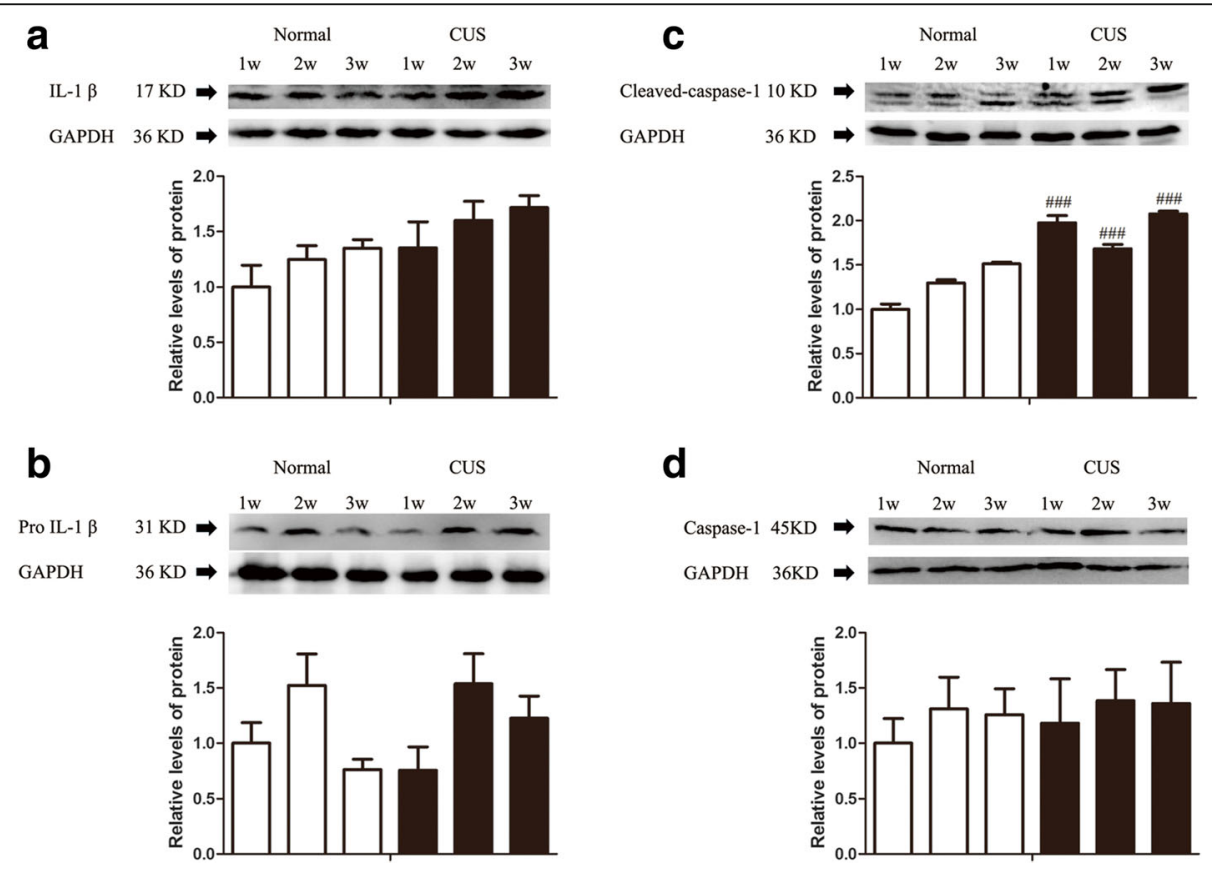

Fig. 2 CUS increases levels of cleaved caspase-1 in the hippocampus of rats. Rats were exposed to CUS for 1, 2, and 3 weeks, respectively, and hippocampi were collected and analyzed for levels of (a) IL-1 $\beta$ ( $n=4$ per group), (b) pro-IL-1 $\beta$ ( $n=4$ per group), (c) cleaved caspase-1 ( $n=4$ per group), and (d) caspase-1 ( $n=4$ per group) using western blotting. Results are expressed as the mean \pm SEM. \#\#\# $p<0.001$ compared to normal rats at the same time point 

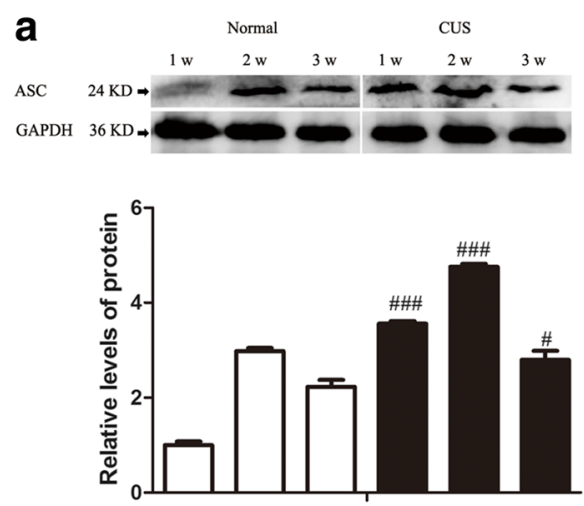

\section{C}

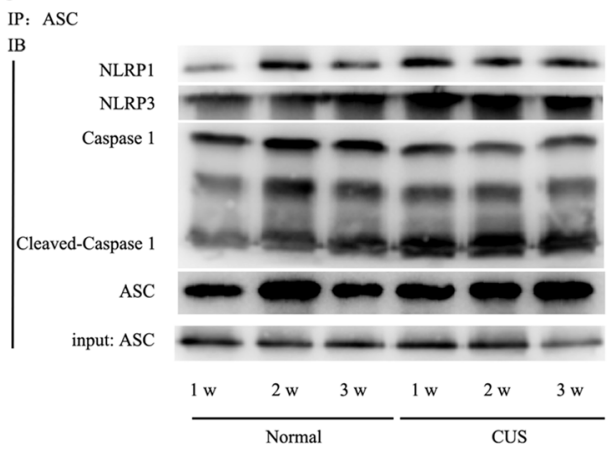

d

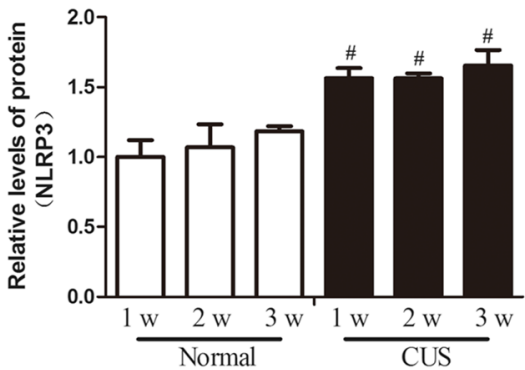

b
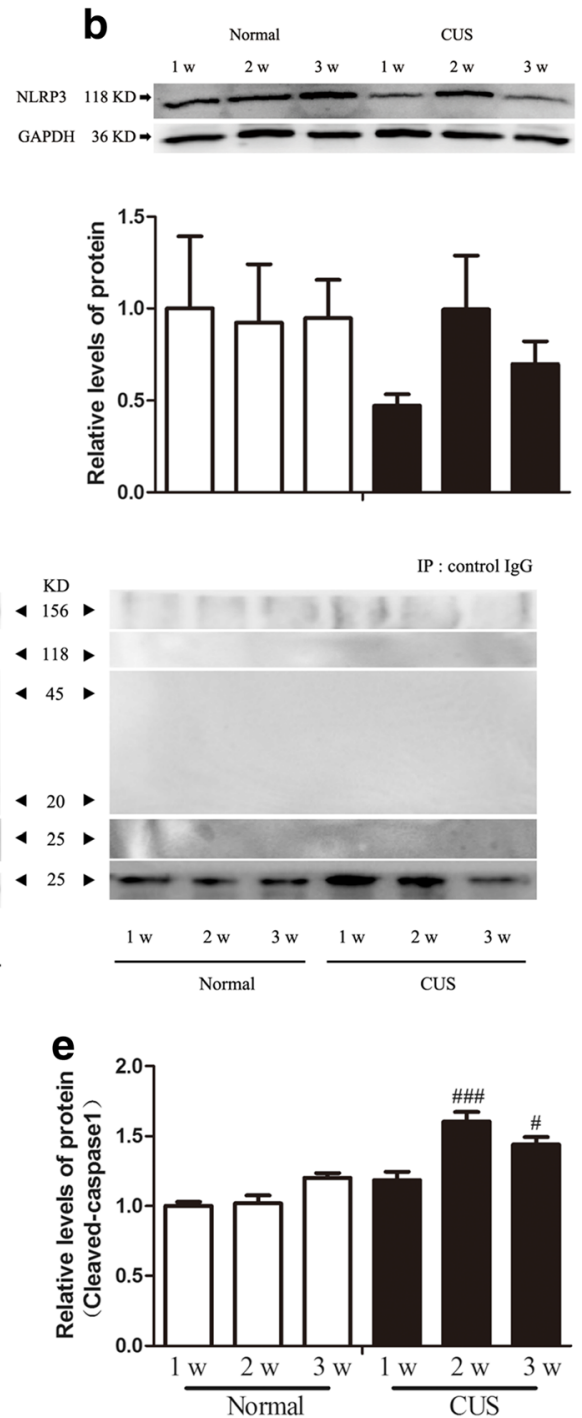

Fig. 3 CUS increases levels of ASC and activates the NLRP3 inflammasome. a, b Rats were exposed to CUS for 1, 2, and 3 weeks, respectively, and hippocampi were collected and analyzed for levels of NLRP3 and ASC using western blotting. Quantification of the changes of NLRP3 and ASC between the groups ( $n=4$ per group). c Co-immunoprecipitation assay was operated to determine the assembly of NLRP1/3 inflammasome in the hippocampus of rats subjected to different treatments anti-ASC antibody coupled beads or lgG control using western blotting. $\mathbf{d}$, e Quantification of the protein changes of NLRP3 and cleaved caspase-3 according to the co-immunoprecipitation assay results ( $n=4$ per group). ${ }^{\#}<<0.05$, ${ }^{\# \# \# ~} p<0.001$ compared to normal rats at the same time point

this aim, we treated the rats with CUS in combination with two types of antagonists of P2X7R, respectively (Fig. 4a, b). Compared to the normal group, the stressed rats exhibited a typical depressive-like behavior after 3 weeks of CUS, such as reduced rearing times and total distance traveled in OFT (Fig. 4c, d), and less struggle and extended immobility in FST (Fig. 4e, f). Meanwhile, the behavior deficits induced by CUS were blocked by hippocampal infuse with the antagonist of P2X7R, BBG, and A438079, respectively (Fig. 4c-f).
CUS could not induce depressive-like behavior in P2X7-null mice

Based on the previous results, we further tested the wild-type male C57BL6/J and mutant male P2X7-null mice in CUS paradigms (Fig. 5a). The results show that CUS induced significant depressive-like behaviors in wild-type C57BL6/J mice, such as more immobility time in the FST and less rearing time in the OFT but not in P2X7-null mice (significant stressor treatment $x$ genotype interactions) (Fig. 5b, c). Simultaneously, CUS stress did not affect both wild-type and P2X7-null mice 

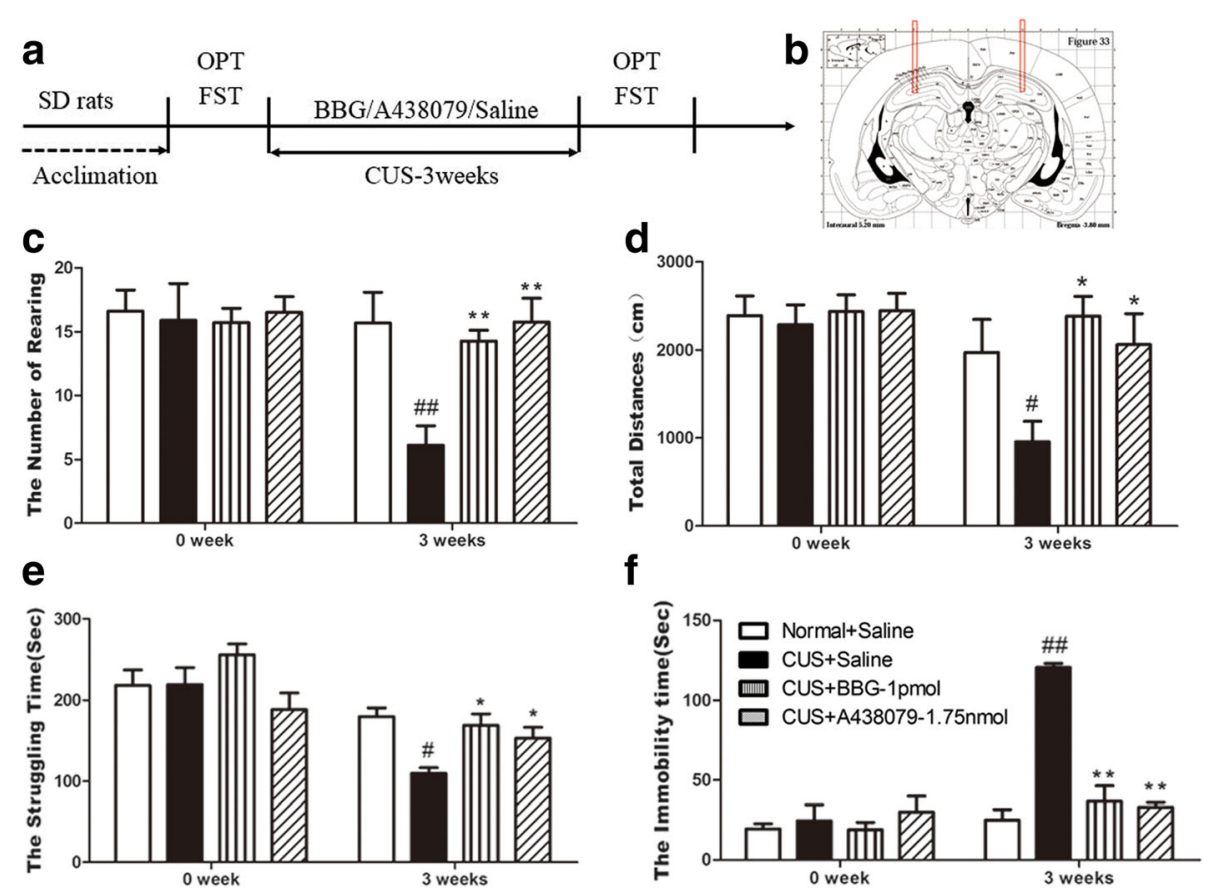

Fig. 4 P2X7 receptor antagonism impeded the development of depressive-like behaviors induced by CUS. (a-f) Influence of A438079 or BBG on behavioral deficits induced by chronic unpredictable stress (CUS). a Experimental paradigm. Rats were randomly divided into four groups: normal + saline $(n=13)$, CUS + saline $(n=11)$, CUS + BBG $(n=11)$, and CUS + A438079 $(n=13)$. All rats in CUS groups were exposed to CUS with antagonist of P2X7 receptor (BBG, 1 pmol/rat; A438079, $1.75 \mathrm{nmol} /$ rat) or vehicle administration in the hippocampus per day for 3 weeks. b A schematic representation of hippocampi sections. Bars indicate the placement of the guide cannulas ( $3.8 \mathrm{~mm}$ anteroposterior; $\pm 3 \mathrm{~mm}$ mediolateral from bregma; $3.5 \mathrm{~mm}$ dorsoventral from the skull). Behavioral tests were then conducted, including $\mathbf{c}$ rearing numbers in open-field test $(\mathrm{OFT})\left(F_{3,47}=6.030, p<0\right.$ .01), (d) total distance traveled in open-field test (OFT) $\left(F_{3,47}=3.518, p<0.05\right)$, e struggling time in forced swimming test (FST) $\left(F_{3,47}=6.537, p<0.05\right)$, f immobility time in forced swimming test (FST) $\left(F_{3,47}=60.660, p<0.01\right)$. All data are expressed as the mean \pm SEM. ${ }^{\#} p<0.05$, ${ }^{\#} p<0.01$, comparing to normal rats; ${ }^{*} p<0.05,{ }^{* *} p<0.01$ compared to rats in CUS + saline group

locomotor activity in OFT (Fig. 5d). Interestingly, the P2X7-null groups reported greater symptoms of anxiety, regardless of whether being exposed to CUS [open-arm entrance percent (stressor treatment $\times$ genotype interactions); open-arm time percent (main effect of genotype)] (Fig. 5e, f). We also tested the female wild-type and female P2X7-null C57BL/6 mice in the same CUS paradigms. It was suggested that there was no significant difference between the sexes (Additional file 2: Figure S2).

\section{Chronic treatment with agonists of P2X7R-induced depressive-like behaviors}

Since CUS can cause eATP to increase in the hippocampus and induce significant depressive-like behaviors, does ATP mediate the effect of stress on depressive-like behaviors via prolonged activation of P2X7R in rats? We further evaluated the effect of agonists of P2X7R (ATP and BzATP) in rats (Fig. 6a, b). As shown in Fig. 6, the rats showed decreased rearing times and reduced total distances in the OFT (Fig. 6c, d), and less struggle and more immobility in the FST (Fig. 6e, f) after being microinjected with ATP or BzATP for 3 weeks. This finding suggests that prolonged ATP or BzATP treatment causes the classic depressive-like behaviors.

\section{Discussion}

The present study shows that stress accumulation causes an increase in extracellular ATP, the assembly of NLRP3 inflammasome, the cleavage of caspase-1, mature of IL$1 \beta$ in the hippocampus as well as the depressive-like and anxiety-like behaviors in rodents. Hippocampal infuse of P2X7R agonist can cause significant behavioral deficits as exposure to CUS. In contrast, the behavioral deficits caused by CUS are impeded by pretreatment with a P2X7R antagonist or permanently knockout of P2X7R, suggesting that increased eATP activates P2X7R to mediate the development of behavioral deficits caused by CUS. Then, further studies are needed to clarify the source of extracellular ATP and to identify the receptors that mediate the release of ATP.

As we know, elevated extracellular ATP is necessary for P2X7R activation [56]. Only a very few studies [57-60] focuses on the change of eATP, endogenous ligand of P2X7R in any brain areas, although there are increasing studies that have demonstrated the important pathophysiological 

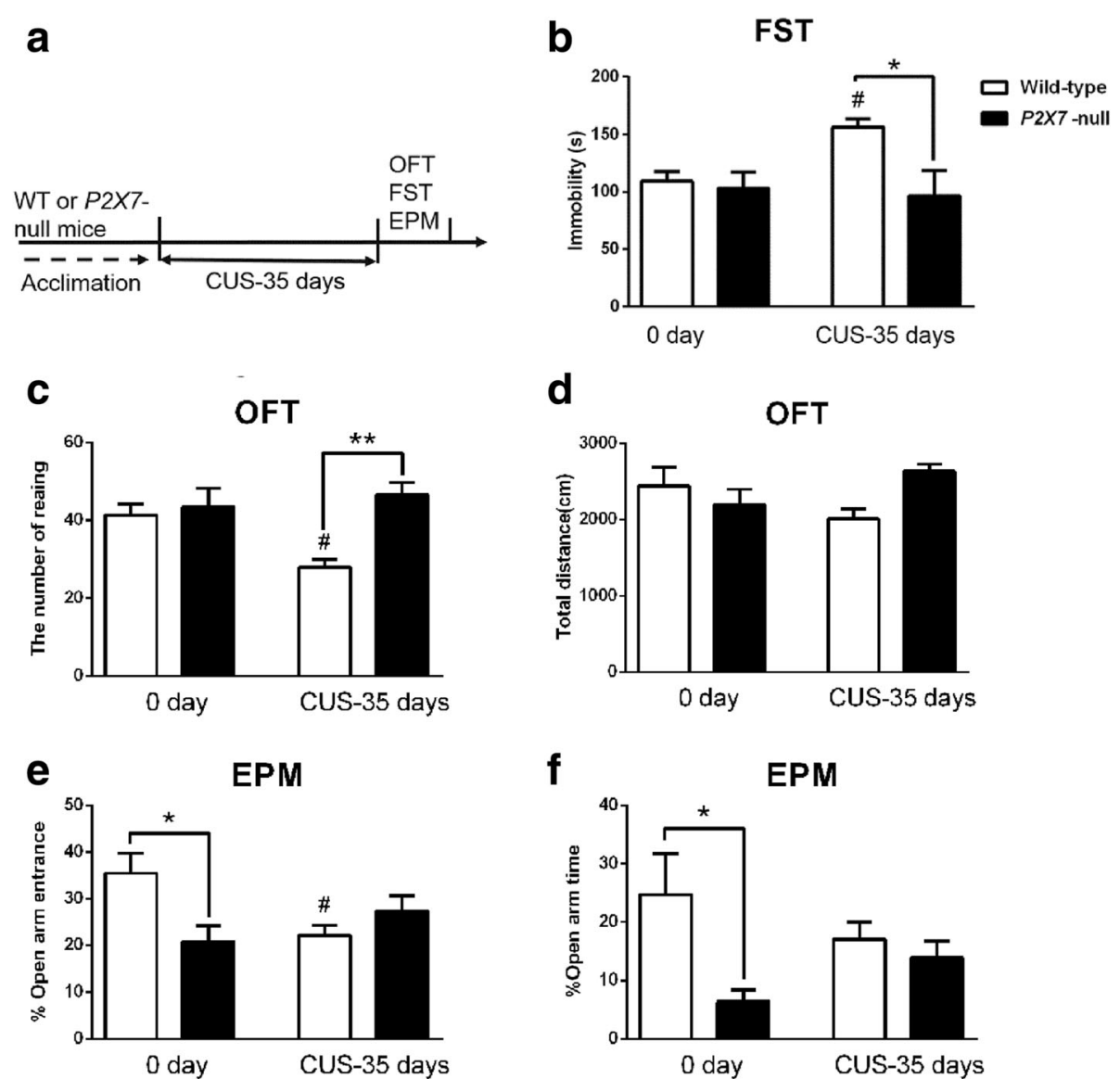

Fig. 5 CUS induced depression-like behavior in wild-type C57BL6/J mice but not in mutant P2X7-null mice. a Experimental paradigm. Wild-type C57BL6/J (WT) and mutant P2X7-null mice were exposed to CUS for 35 days. Behavioral indicators were then assessed, including (b) immobility time in forced swimming test (FST) (interaction: $F_{1,37}=4.501, p<0.05$; genotype: $F_{1,37}=6.862, p<0.05$ ), c rearing numbers in open-field test (OFT) (interaction: $F_{1,37}=6.204, p<0.05$; genotype: $F_{1,37}=9.971, p<0.01$ ), (d) total distance in open-field test (OFT) (interaction: $F_{1,37}=4.918$, $p<0.05$ ), e Open-arm entrance percent in elevated plus maze test (EPM) (interaction: $F_{1,34}=8.381, p<0.01$ ), and (f) open-arm time percent in elevated plus maze test (EPM) (genotype: $F_{1,34}=5.194, p<0.05$ ). $n=8-12$ per group; all data are expressed as the mean \pm SEM. ${ }^{*} p<0.05$ and ${ }^{* *} p<0.01$, comparing genotypes. ${ }^{*} p<0.05$, comparing treatment

functions of P2X7R in CNS disorders, including neuropathic pain [61], trauma brain injury [62], and neurodegenerative illnesses $[60,63]$. In recent years, there are only two papers that detected the levels of eATP in the hippocampus in animal model of depression $[64,65]$. The results of these two papers are conflicted with each other. Inconsistent with the latter [64], our results present that eATP level was increased progressively in the hippocampus following chronic stress accumulation, although their results suggested that ATP is released during stress exposure [64]. And they also could not illuminate the sources of eATP. As they said, the neuron [66] and astrocyte [67] could be the source of eATP. Meanwhile, eATP, as a "warning molecule" or "danger signal", is a trigger for microglial activation, and P2X7R could be the major mediator of this effect [68-71]. Even if the results confirmed the hypothesis, further studies should be done to clarify the precise mechanism which mediated stress-induced ATP release in the hippocampus.
There is strong evidence that neuroinflammation may play a key role in the development of affective disorders including depression and anxiety $[7,9]$. In clinical, ischemia stroke [72], autoimmune multiple sclerosis (MS) [73], and some neurodegenerative diseases [74], which are characterized by significant neuroinflammation, have high rates of comorbidity with depression. A growing body of evidence has confirmed that the activation of microglia and overproduction of proinflammatory cytokines in some brain areas are associated with the development of these diseases [75-78]. Many studies of depression [79-82] have demonstrated peripheric inflammation activation, including elevated levels of IL-1 $\beta$, IL- 6 and interferon- $\gamma$ (IFN- $\gamma$ ) in peripheral circulation in depressive patients or animal model of depression, but only several studies observed the increased concentration of IL-1 $\beta$ in some brain regions in animal model of depression[33, 83, 84]. In recent years, 

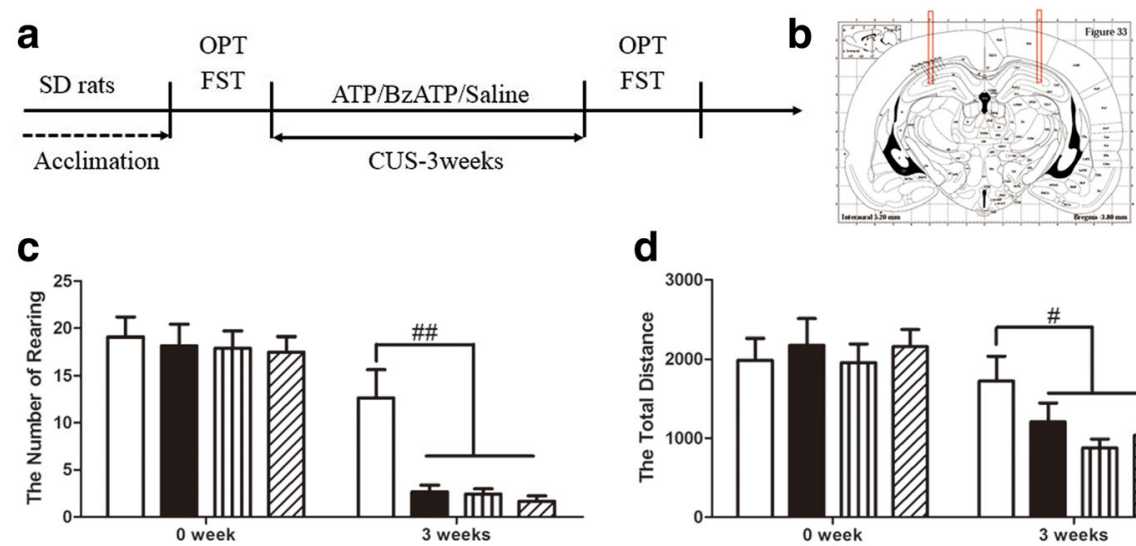

d
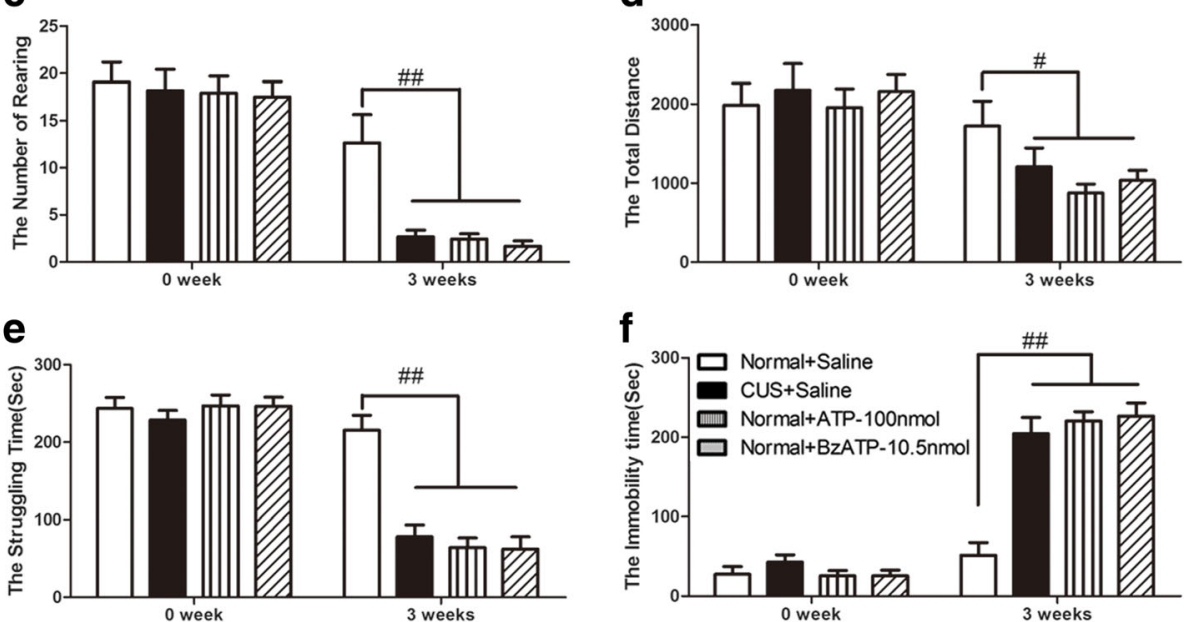

Fig. 6 P2X7 receptor agonist administration induces depressive-like behaviors. a-f ATP or BzATP causes depressive-like behaviors which are the same as chronic unpredictable stress (CUS). a Experimental paradigm. Rats were randomly divided into four groups: normal + saline ( $n=11)$, CUS + saline $(n=12)$, normal + ATP $(n=12)$, normal + BzATP $(n=12)$. All rats in CUS group were exposed to CUS with vehicle administration for 3 weeks; meanwhile, rats in ATP or BzATP group were administered with ATP (100 nmol/rat) or BzATP (10 nmol/rat), respectively, per day for 3 weeks. b A schematic representation of hippocampi sections. Bars indicate the placement of the guide cannulas ( $3.8 \mathrm{~mm}$ anteroposterior; $\pm 3 \mathrm{~mm}$ mediolateral from bregma; $3.5 \mathrm{~mm}$ dorsoventral from the skull). Behavioral indicators were then assessed, including (c) rearing numbers in open-field test (OFT) $\left(F_{3,46}=11.502, p<0.01\right)$, (d) total distance traveled in open-field test (OFT) $\left(F_{3,46}=2.971, p<0.05\right)$, (e) struggling time in forced swimming test (FST) $\left(F_{3,46}=20.868, p<0.01\right)$, and $(\mathbf{f})$ immobility time in forced swimming test $(F S T)\left(F_{3,46}=24.357, p<0.01\right)$ All data are expressed as the mean \pm SEM. ${ }^{\#} p<0.05,{ }^{\# \#} p<0.01$ compared to normal rats

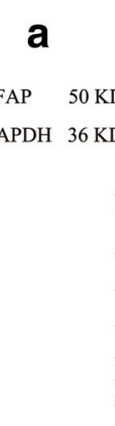

C

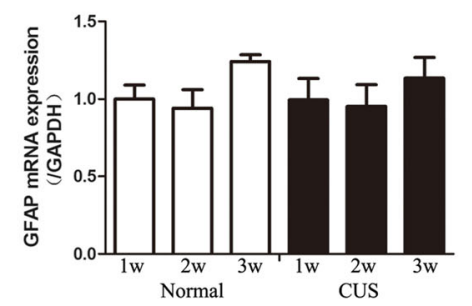

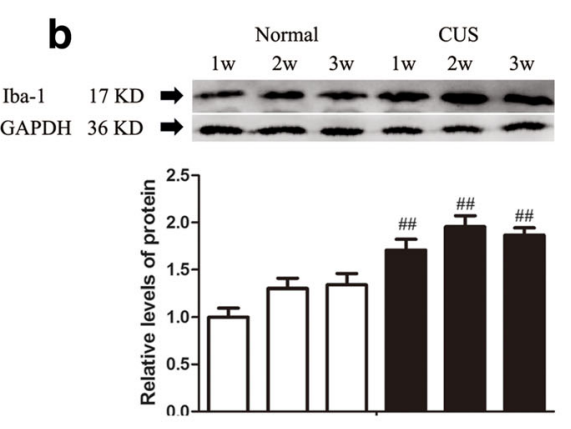

d

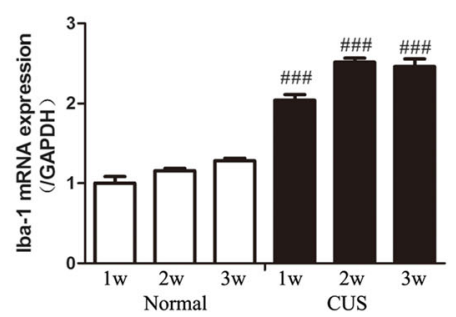

Fig. 7 CUS could significantly increase the expression of Iba-1 in the hippocampus of rats in early stage. Western blots of GFAP (a) and Iba-1 (b) in the hippocampus. GFAP (c) and Iba-1 (d) mRNA level in different groups were expressed as a ratio to that of corresponding GAPDH. Results are expressed as the mean \pm SEM $\left(n=4\right.$ per group). ${ }^{\# \#} p<0.05$, ${ }^{\# \# \#} p<0.001$ compared to normal rats at the same time point 
activated microglia was regarded as the source of local synthesized cytokines in brain. But, the research focus on microglia in depression presented paradoxical results [85-89]. Our results showed that following the stress accumulation, except interleukin-1beta level were increased, Iba-1, an activated marker of microglia were consistently increased, which hinting that microglia in the hippocampus exhibited an activated statement following chronic stress (Fig. 7). However, the activated type and precise role of microglia response to chronic stress merited further investigation.

As mentioned above, activated microglia could be the key source of neuroinflammatory cytokines, including IL- $1 \beta$ and the major mediator of many neuroinflammatory diseases [90, 91]. Consistently with some previous studies [92], our results exhibited that P2X7R is predominantly localized to microglia throughout the CNS. Thus, P2X7R may be responsible for stress-induced microglia activation. In addition, extracellular ATP-induced P2X7R activation could directly mediate $\mathrm{K}+$ efflux which has been proposed to account for NLRP3 activation [93, 94]. Recently, several studies has also reported the change of NLRP3 inflammasome in rodents upon CUMS, LPS stimulus, or estrogen deficiency [95-97]. In their studies, they observed the overexpression of some components of NLRP3 inflammasome but did not detect the assembly of NLRP3 inflammasome. In accordance with their results, our results also showed that ASC, one of the components of NLRP3 inflammasome, are overexpressed. Except that we also observed that following the stress accumulation, the activation of NLRP3 inflammasome were increased, which were indicated by the oligomerization of NLRP3 with ASC and pro-caspase-1 and the cleavage $\mathrm{f}$ caspase-1. In accordance with our results, Ma et al. [98] indicated that NLRP3 primarily colocalized with microglia, providing further support for a tight relationship between P2X7R and NLRP3. Taken together, it implied that P2X7R may be responsible for chronic stress-induced neuroinflammation, possibly by NLRP3 inflammasome-dependent IL-1 $\beta$ mature and microglia activation.

In consistent with previous report [64], our results exhibited that chronic hippocampal infuse of two selective P2X7 antagonists, BBG and A438079, completely impeded the development of the depressive- and anxiety-like behaviors resulting from chronic stress. The similar effects have also been observed in P2X7R-null mice in this research as with the two earlier studies [27]. It has been reported that P2X7R antagonist rapidly blocks the induction of IL-1 $\beta$ by acute stress but does not produce a response in acute behavioral models [64]. In addition, previous studies have indicated that BBG inhibited the inflammatory response via the P2X7R/ NLRP3 axis following intracerebral hemorrhage [99].
Combined with these previous findings, our results hinted that chronic stress causes eATP accumulation and sustained activation of P2X7R/NLRP3 axis. However, further research is merited to clarify whether the NLRP3 inflammasome is a key mediator of P2X7 blockage-induced antineuroinflammation and antidepressant-like effects.

\section{Conclusions}

Chronic stress increases eATP level and then leads to neuroinflammation in the hippocampus, eventually leading to depression-like and anxiety-like behavior in rodents. P2X7R agonist also causes depression-like and anxietylike behavior in rodents as chronic stress. In contrast, P2X7R blockage or null mutation of P2X7R is effective approach for blocking the deleterious effects or chronic stress on depressive and anxiety behaviors. Together, our data imply that P2X7/NLRP3 axis could be the potential therapeutic target for stress-induced affective disorders.

\section{Additional files}

Additional file 1: Figure S1. Expression of $P 2 X 7$ receptors in hippocampus. (A-I) Immunofluorescence staining of hippocampal sections from normal rats. P2X7R (green), Iba-1 (red), GFAP(red), DAPI(blue), $\times 40$ objective; scale bar, $50 \mu \mathrm{m}$. (J) Percentage of P2X7 receptor-immunopositive cells. Three regions per hippocampus section and three sections per animal were counted by experimenters who were blind to the experiment design. (TIF $10328 \mathrm{~kb}$ )

Additional file 2: Figure S2. There was no significant sexual difference in the mice model of depression induced by chronic unpredictable stress. (A) Experimental paradigm. Wild-type C57BL6/J (WT) male and female mice were exposed to CUS for 35 days. Behavioral indicators were then assessed, including (B) immobility time in forced swimming test (FST) (interaction: $F_{1,34}=0.0003, p=0.9857$; stress: $F_{1,34}=26.51, p<0.0001$; sex: $\left.F_{1,34}=0.4940, p=0.4869\right)$, $(C)$ the number of rearing in open-field test (OFT) (interaction: $F_{1,34}=0.01154, p=0.9151$; stress: $F_{1,34}=20.44, p<$ 0.0001 ; sex: $\left.F_{1,34}=0.1414, p=0.7092\right)$, (D) total distance in open-field test (OFT) (interaction: $F_{1,34}=0.03584, p=0.8510$; stress: $F_{1,34}=4.501$, $p=0.0412$; sex: $\left.F_{1,34}=0.1341, p=0.7165\right)$, (E) open-arm entrance percent in elevated plus maze test (EPM) (interaction: $F_{1,34}=0.1817, p=0.6728$; stress: $F_{1,34}=16.47, p=0.0003$; sex: $\left.F_{1,34}=7.879, p=0.0084\right)$, (F) open-arm time percent in elevated plus maze test (EPM) (interaction: $F_{1,34}=0.7491$, $p=0.3932$; stress: $F_{1,34}=5.100, p=0.0309$; sex: $F_{1,34}=0.2789, p=0.6011$ ) $n=8-12$ per group, all data are expressed as the mean \pm SEM. ${ }^{*} p<0.05$, ${ }^{\# \#} p<0.01$, \#\# $p<0.001$, compared to male before CUS. ${ }^{*} p<0.05$ and ${ }^{* *} p<0.01$, compared to female before CUS. (G) Experimental paradigm. Wild-type C57BL6/J (WT) and P2X7-null female mice were exposed to CUS for 35 days. Behavioral indicators were then assessed, including $(\mathrm{H})$ immobility time in forced swimming test (FST) (interaction: $F_{1,23}=1.038$, $p=0.3188$; stress: $F_{1,23}=8.155, p=0.0089$; genotype: $F_{1,23}=1.610$,

$p=0.2171$ ), (I) the number of rearing in open-field test (OFT) (interaction: $F_{1,23}=3.690, p=0.0672 ;$ stress: $F_{1,23}=3.929, p=0.0595 ;$ genotype: $F_{1,23}=$ $1.221, p=0.2805),(J)$ total distance in open-field test (OFT) (interaction: $\mathrm{F}_{1,23}=4.348, p=0.0483$; stress: $\mathrm{F}_{1,23}=0.2596, p=0.6153$; genotype: $\mathrm{F}_{1,23}=$ $2.684, p=0.1150)$, (K) open-arm entrance percent in elevated plus maze test (EPM) (interaction: $\mathrm{F}_{1,23}=5.294, p=0.0308$; stress: $\mathrm{F}_{1,23}=2.595$, $p=0.1208$; genotype: $\left.F_{1,23}=1.976, p=0.1732\right)$, and $(L)$ open-arm time percent in elevated plus maze test (EPM) (interaction: $F_{1,23}=5.914$, $p=0.0232$; stress: $F_{1,23}=3.100, p=0.0916$; genotype: $F_{1,23}=3.463$, $p=0.0756) . n=5-8$ per group, all data are expressed as the mean \pm

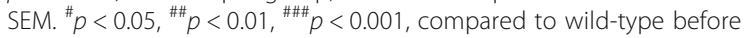
CUS. $p<0.05$, comparing genotypes. (TIF $9760 \mathrm{~kb}$ ) 


\section{Abbreviations}

ACSF: Artificial cerebrospinal fluid; ARL 67156 trisodium salt: 6-N, N-diethyl- $\beta$ $\gamma$-dibromomethylene-D-adenosine-5-triphosphate FPL 67156; CUS: Chronic unpredictable stress; IL-1 $\beta$ : Interleukin-1 $\beta$; IP: Immunoprecipitation; P2X7R: P2X7 receptor

\section{Acknowledgements}

We would like to thank Jian-Wei Jiang for the expert technical assistance.

\section{Funding}

This work was supported by the National Natural Science Foundation of China (Grant No. 81671349, No. 31371083, No. 81071103, No. 81473437, and No. 81271500) and the Development Project of Shanghai Peak Disciplines-Integrated Chinese and Western Medicine.

\section{Availability of data and materials}

Please contact author for data requests.

\section{Authors' contributions}

NY and JY designed the research; NY, HJH, XCZ, QQH, YLW, and BL performed the research; $Y Q Z$ and $J Y$ coordinated and supervised the study. $N Y, H J H, Q L, G C W, Y Q Z$, and JY were responsible of the design of the study and the interpretation of the results. NY, HJH, and JY conducted the statistical analysis and the draft of the manuscript. All authors read and approved the final manuscript.

\section{Competing interests}

The authors declare that they have no competing interests.

\section{Consent for publication}

Not applicable.

\section{Ethics approval}

All animal experiments were approved by the Experimental Animal Ethics Committee of Shanghai Medical College, Fudan University.

\section{Publisher's Note}

Springer Nature remains neutral with regard to jurisdictional claims in published maps and institutional affiliations.

\section{Author details}

'Department of Integrative Medicine and Neurobiology, School of Basic Medical Sciences, Institues of Brain Science, State Key Laboratory of Medical Neurobiology and Collaborative Innovation Center for Brain Science, Fudan University, Shanghai 200032, China. ${ }^{2}$ Department of Anatomy, Histology and Embryology, School of Basic Medical Sciences, Shanghai Medical College, Fudan University, Shanghai 200032, China. ${ }^{3}$ Key Laboratory of Medical Imaging Computing and Computer Assisted Intervention of Shanghai, Shanghai 200032, China.

Received: 17 February 2017 Accepted: 14 April 2017

Published online: 10 May 2017

\section{References}

1. Nemeroff CB, Kalali A, Keller MB, Charney DS, Lenderts SE, Cascade EF, Stephenson $\mathrm{H}$, Schatzberg AF. Impact of publicity concerning pediatric suicidality data on physician practice patterns in the United States. Arch Gen Psychiatry. 2007;64:466-72.

2. Heim C, Mletzko T, Purselle D, Musselman DL, Nemeroff CB. The dexamethasone/corticotropin-releasing factor test in men with major depression: role of childhood trauma. Biol Psychiatry. 2008;63:398-405

3. Charney DS, Dejesus G, Manji HK. Cellular plasticity and resilience and the pathophysiology of severe mood disorders. Dialogues Clin Neurosci. 2004:6:217-25.

4. Hayden EP, Klein DN, Dougherty LR, Olino TM, Dyson MW, Durbin CE, Sheikh HI, Singh SM. The role of brain-derived neurotrophic factor genotype, parental depression, and relationship discord in predicting earlyemerging negative emotionality. Psychol Sci. 2010;21:1678-85.

5. Franco R, Fernandez-Suarez D. Alternatively activated microglia and macrophages in the central nervous system. Prog Neurobiol. 2015;131:65-86.
6. Iwata M, Ota KT, Duman RS. The inflammasome: pathways linking psychological stress, depression, and systemic illnesses. Brain Behav Immun. 2013;31:105-14.

7. Eyre $H$, Baune BT. Neuroimmunological effects of physical exercise in depression. Brain Behav Immun. 2012;26:251-66.

8. Wager-Smith K, Markou A. Depression: a repair response to stress-induced neuronal microdamage that can grade into a chronic neuroinflammatory condition? Neurosci Biobehav Rev. 2011;35:742-64.

9. Maes M, Yirmyia R, Noraberg J, Brene S, Hibbeln J, Perini G, Kubera M, Bob P, Lerer B, Maj M. The inflammatory \&amp; neurodegenerative (I\&amp;ND) hypothesis of depression: leads for future research and new drug developments in depression. Metab Brain Dis. 2009;24:27-53.

10. Young JJ, Bruno D, Pomara N. A review of the relationship between proinflammatory cytokines and major depressive disorder. J Affect Disord. 2014;169:15-20.

11. Nguyen KT, Deak T, Owens SM, Kohno T, Fleshner M, Watkins LR, Maier SF. Exposure to acute stress induces brain interleukin-1beta protein in the rat. $J$ Neurosci. 1998;18:2239-46.

12. Shintani F, Nakaki T, Kanba S, Sato K, Yagi G, Shiozawa M, Aiso S, Kato R, Asai M. Involvement of interleukin-1 in immobilization stress-induced increase in plasma adrenocorticotropic hormone and in release of hypothalamic monoamines in the rat. J Neurosci. 1995;15:1961-70.

13. Deak T, Bordner KA, McElderry NK, Barnum CJ, Blandino PJ, Deak MM, Tammariello SP. Stress-induced increases in hypothalamic IL-1: a systematic analysis of multiple stressor paradigms. Brain Res Bull. 2005;64:541-56.

14. Sapolsky R, Rivier C, Yamamoto G, Plotsky P, Vale W. Interleukin-1 stimulates the secretion of hypothalamic corticotropin-releasing factor. Science. 1987;238:522-4.

15. Murray CA, Lynch MA. Evidence that increased hippocampal expression of the cytokine interleukin-1 beta is a common trigger for age- and stressinduced impairments in long-term potentiation. J Neurosci. 1998;18:2974-81.

16. Pugh CR, Nguyen KT, Gonyea JL, Fleshner M, Wakins LR, Maier SF, Rudy JW. Role of interleukin-1 beta in impairment of contextual fear conditioning caused by social isolation. Behav Brain Res. 1999;106:109-18.

17. Kovacs D, Eszlari N, Petschner P, Pap D, Vas S, Kovacs P, Gonda X, Juhasz G, Bagdy $\mathrm{G}$. Effects of IL1B single nucleotide polymorphisms on depressive and anxiety symptoms are determined by severity and type of life stress. Brain Behav Immun. 2016;56:96-104.

18. Koo JW, Duman RS. IL-1 beta is an essential mediator of the antineurogenic and anhedonic effects of stress. Proc Natl Acad Sci U S A. 2008;105:751-6.

19. Koo JW, Russo SJ, Ferguson D, Nestler EJ, Duman RS. Nuclear factor-kappaB is a critical mediator of stress-impaired neurogenesis and depressive behavior. Proc Natl Acad Sci U S A. 2010;107:2669-74.

20. Piccini A, Carta S, Tassi A, Lasiglie D, Fossati G, Rubartelli A. ATP is released by monocytes stimulated with pathogen-sensing receptor ligands and induces IL-1beta and IL-18 secretion in an autocrine way. Proc Natl Acad Sci U S A. 2008;176:8067-72.

21. Potucek YD, Crain JM, Watters JJ. Purinergic receptors modulate MAP kinases and transcription factors that control microglial inflammatory gene expression. Neurochem Int. 2006;49:204-14.

22. Mingam R, De Smedt V, Amedee T, Bluthe RM, Kelley KW, Dantzer R, Laye S. In vitro and in vivo evidence for a role of the P2X7 receptor in the release of IL-1 beta in the murine brain. Brain Behav Immun. 2008;22:234-44.

23. Ferrari D, Pizzirani C, Adinolfi E, Lemoli RM, Curti A, Idzko M, Panther E, Di Virgilio F. The P2X7 receptor: a key player in IL-1 processing and release. J Immunol. 2006;176:3877-83.

24. Murphy N, Lynch MA. Activation of the P2X (7) receptor induces migration of glial cells by inducing cathepsin B degradation of tissue inhibitor of metalloproteinase 1. J Neurochem. 2012;123:761-70.

25. Lucae S, Salyakina D, Barden N, Harvey M, Gagne B, Labbe M, Binder EB, Uhr M, Paez-Pereda M, Sillaber I, et al. P2RX7, a gene coding for a purinergic ligand-gated ion channel, is associated with major depressive disorder. Hum Mol Genet. 2006;15:2438-45.

26. Boucher AA, Arnold JC, Hunt GE, Spiro A, Spencer J, Brown C, McGregor IS, Bennett MR, Kassiou M. Resilience and reduced c-Fos expression in P2X7 receptor knockout mice exposed to repeated forced swim test. Neuroscience. 2011;189:170-7.

27. Basso AM, Bratcher NA, Harris RR, Jarvis MF, Decker MW, Rueter LE. Behavioral profile of $\mathrm{P} 2 \mathrm{X} 7$ receptor knockout mice in animal models of depression and anxiety: relevance for neuropsychiatric disorders. Behav Brain Res. 2009;198:83-90. 
28. Csolle C, Baranyi M, Zsilla G, Kittel A, Goloncser F, Illes P, Papp E, Vizi ES, Sperlagh B. Neurochemical changes in the mouse hippocampus underlying the antidepressant effect of genetic deletion of P2X7 receptors. PLoS One. 2013;8:e66547.

29. Jin C, Flavell RA. Molecular mechanism of NLRP3 inflammasome activation. J Clin Immunol. 2010;30:628-31.

30. Gross O, Thomas CJ, Guarda G, Tschopp J. The inflammasome: an integrated view. Immunol Rev. 2011;243:136-51.

31. Davis BK, Wen H, Ting JP. The inflammasome NLRs in immunity, inflammation, and associated diseases. Annu Rev Immunol. 2011;29:707-35.

32. Schroder K, Tschopp J. The inflammasomes. Cell. 2010;140:821-32.

33. Zhang $Y$, Liu L, Liu YZ, Shen XL, Wu TY, Zhang T, Wang W, Wang YX, Jiang $\mathrm{CL}$ : NLRP3 inflammasome mediates chronic mild stress-induced depression in mice via neuroinflammation. Int J Neuropsychopharmacol 2015, 18

34. Alcocer-Gomez E, Cordero MD. NLRP3 inflammasome: a new target in major depressive disorder. CNS Neurosci Ther. 2014;20:294-5.

35. Yang L, Yue N, Zhu X, Han Q, Liu Q, Yu J, Wu G. Electroacupuncture upregulates ERK signaling pathways and promotes adult hippocampal neural progenitors proliferation in a rat model of depression. BMC Complement Altern Med. 2013;13:288

36. Li B, Yang CJ, Yue N, Liu Y, Yu J, Wang YQ, Liu Q, Wu GC. Clomipramine reverses hypoalgesia/hypoesthesia and improved depressive-like behaviors induced by inescapable shock in rats. Neurosci Lett. 2013;541:227-32.

37. Huang HJ, Zhu XC, Han QQ, Wang YL, Yue N, Wang J, Yu R, Li B, Wu GC, Liu Q, Yu J. Ghrelin alleviates anxiety- and depression-like behaviors induced by chronic unpredictable mild stress in rodents. Behav Brain Res. 2017;326:33-43.

38. Yang L, Shi LJ, Yu J, Zhang YQ. Activation of protein kinase $A$ in the amygdala modulates anxiety-like behaviors in social defeat exposed mice. Mol Brain. 2016;9:3.

39. Hibell AD, Thompson KM, Simon J, Xing M, Humphrey PP, Michel AD. Species- and agonist-dependent differences in the deactivation-kinetics of P2X7 receptors. Naunyn Schmiedebergs Arch Pharmacol. 2001;363:639-48.

40. Zhao H, Zhang X, Dai Z, Feng Y, Li Q, Zhang JH, Liu X, Chen Y, Feng H. P2X7 receptor suppression preserves blood-brain barrier through inhibiting RhoA activation after experimental intracerebral hemorrhage in rats. Sci Rep. 2016;6:23286.

41. Jimenez-Pacheco A, Mesuret G, Sanz-Rodriguez A, Tanaka K, Mooney C, Conroy R, Miras-Portugal MT, Diaz-Hernandez M, Henshall DC, Engel T. Increased neocortical expression of the P2X7 receptor after status epilepticus and anticonvulsant effect of P2X7 receptor antagonist A-438079. Epilepsia. 2013;54:1551-61

42. Chen S, Ma Q, Krafft PR, Chen Y, Tang J, Zhang J, Zhang JH. P2X7 receptor antagonism inhibits p38 mitogen-activated protein kinase activation and ameliorates neuronal apoptosis after subarachnoid hemorrhage in rats. Crit Care Med. 2013:41:e466-74.

43. Chen S, Ma Q, Krafft PR, Hu Q, Rolland WN, Sherchan P, Zhang J, Tang J, Zhang JH. P2X7R/cryopyrin inflammasome axis inhibition reduces neuroinflammation after SAH. Neurobiol Dis. 2013;58:296-307.

44. Kim JE, Ryu HJ, Kang TC. P2X7 receptor activation ameliorates CA3 neuronal damage via a tumor necrosis factor-alpha-mediated pathway in the rat hippocampus following status epilepticus. J Neuroinflammation. 2011;8:62.

45. Ducottet C, Aubert A, Belzung C. Susceptibility to subchronic unpredictable stress is related to individual reactivity to threat stimuli in mice. Behav Brain Res. 2004:155:291-9.

46. Willner P. Chronic mild stress (CMS) revisited: consistency and behaviouralneurobiological concordance in the effects of CMS. Neuropsychobiology. 2005;52:90-110.

47. Willner P. Validity, reliability and utility of the chronic mild stress model of depression: a 10-year review and evaluation. Psychopharmacology (Berl). 1997;134:319-29.

48. Katz RJ, Roth KA, Carroll BJ. Acute and chronic stress effects on open field activity in the rat: implications for a model of depression. Neurosci Biobehav Rev. 1981:5:247-51.

49. Mineur YS, Belzung C, Crusio WE. Functional implications of decreases in neurogenesis following chronic mild stress in mice. Neuroscience. 2007;150:251-9.

50. Li Q, Tian Y, Wang ZF, Liu SB, Mi WL, Ma HJ, Wu GC, Wang J, Yu J, Wang $Y Q$. Involvement of the spinal NALP1 inflammasome in neuropathic pain and aspirin-triggered-15-epi-lipoxin A4 induced analgesia. Neuroscience. 2013;254:230-40
51. Stoffels M, Zaal R, Kok N, van der Meer JW, Dinarello CA, Simon A. ATPinduced IL-1beta specific secretion: true under stringent conditions. Front Immunol. 2015;6:54.

52. Heneka MT, Kummer MP, Latz E. Innate immune activation in neurodegenerative disease. Nat Rev Immunol. 2014;14:463-77.

53. Lu Y, Xiao G, Luo W. Minocycline suppresses NLRP3 inflammasome activation in experimental ischemic stroke. Neuroimmunomodulat. 2016;23(4):230-238.

54. Gustin A, Kirchmeyer M, Koncina E, Felten P, Losciuto S, Heurtaux T, Tardivel A, Heuschling P, Dostert C. NLRP3 inflammasome is expressed and functional in mouse brain microglia but not in astrocytes. PLoS One. 2015;10:e130624.

55. Heneka MT, Kummer MP, Stutz A, Delekate A, Schwartz S, Vieira-Saecker A, Griep A, Axt D, Remus A, Tzeng TC, et al. NLRP3 is activated in Alzheimer's disease and contributes to pathology in APP/PS1 mice. Nature. 2013:493:674-8.

56. Chessell IP, Hatcher JP, Bountra C, Michel AD, Hughes JP, Green P, Egerton J, Murfin M, Richardson J, Peck WL, Grahames CB, Casula MA, Yiangou Y, Birch R, Anand P, Buell GN. Disruption of the P2X7 purinoceptor gene abolishes chronic inflammatory and neuropathic pain. Pain. 2005:114(3):386-96.

57. Franke H, Grummich B, Hartig W, Grosche J, Regenthal R, Edwards RH, Illes P, Krugel U. Changes in purinergic signaling after cerebral injury-involvement of glutamatergic mechanisms? Int J Dev Neurosci. 2006;24:123-32.

58. Dona F, Conceicao IM, Ulrich H, Ribeiro EB, Freitas TA, Nencioni AL, Da SFM Variations of ATP and its metabolites in the hippocampus of rats subjected to pilocarpine-induced temporal lobe epilepsy. Purinergic Signal. 2016:12:295-302.

59. Melani A, Corti F, Stephan H, Muller CE, Donati C, Bruni P, Vannucchi MG, Pedata F. Ecto-ATPase inhibition: ATP and adenosine release under physiological and ischemic in vivo conditions in the rat striatum. Exp Neurol. 2012;233:193-204.

60. Melani A, Turchi D, Vannucchi MG, Cipriani S, Gianfriddo M, Pedata F. ATP extracellular concentrations are increased in the rat striatum during in vivo ischemia. Neurochem Int. 2005;47:442-8.

61. Luchting B, Heyn J, Woehrle T, Rachinger-Adam B, Kreth S, Hinske LC, Azad SC. Differential expression of P2X7 receptor and IL-1 beta in nociceptive and neuropathic pain. J Neuroinflammation. 2016;13:100.

62. Wang YC, Cui Y, Cui JZ, Sun LQ, Cui CM, Zhang HA, Zhu HX, Li R, Tian YX, Gao JL. Neuroprotective effects of brilliant blue $G$ on the brain following traumatic brain injury in rats. Mol Med Rep. 2015;12:2149-54.

63. Sperlagh $B$, Illes $P$. P $2 X 7$ receptor: an emerging target in central nervous system diseases. Trends Pharmacol Sci. 2014;35:537-47.

64. Iwata M, Ota KT, Li XY, Sakaue F, Li N, Dutheil S, Banasr M, Duric V, Yamanashi T, Kaneko K, et al. Psychological stress activates the inflammasome via release of adenosine triphosphate and stimulation of the purinergic type 2X7 receptor. Biol Psychiatry. 2016;80:12-22.

65. Cao X, Li LP, Wang Q, Wu Q, Hu HH, Zhang M, Fang YY, Zhang J, Li SJ, Xiong WC, et al. Astrocyte-derived ATP modulates depressive-like behaviors. Nat Med. 2013;19:773-7.

66. North RA. Molecular physiology of P2X receptors. Physiol Rev. 2002;82:1013-67.

67. Davalos D, Grutzendler J, Yang G, Kim JV, Zuo Y, Jung S, Littman DR, Dustin $M L$, Gan WB. ATP mediates rapid microglial response to local brain injury in vivo. Nat Neurosci. 2005:8:752-8.

68. Xu P, Xu Y, Hu B, Wang J, Pan R, Murugan M, Wu LJ, Tang Y. Extracellular ATP enhances radiation-induced brain injury through microglial activation and paracrine signaling via P2X7 receptor. Brain Behav Immun. 2015;50:87-100

69. Shiratori M, Tozaki-Saitoh H, Yoshitake M, Tsuda M, Inoue K. P2X7 receptor activation induces CXCL2 production in microglia through NFAT and PKC/ MAPK pathways. J Neurochem. 2010;114:810-9.

70. Clark AK, Staniland AA, Marchand F, Kaan TK, McMahon SB, Malcangio M. P2X7-dependent release of interleukin-1beta and nociception in the spinal cord following lipopolysaccharide. J Neurosci. 2010;30:573-82.

71. Monif M, Reid CA, Powell KL, Smart ML, Williams DA. The P2X7 receptor drives microglial activation and proliferation: a trophic role for $\mathrm{P} 2 \mathrm{X} 7 \mathrm{R}$ pore. $J$ Neurosci. 2009;29:3781-91.

72. Benatti C, Blom JM, Rigillo G, Alboni S, Zizzi F, Torta R, Brunello N, Tascedda F. Disease-induced neuroinflammation and depression. CNS Neurol Disord Drug Targets. 2016:15:414-33.

73. Turner AP, Alschuler KN, Hughes AJ, Beier M, Haselkorn JK, Sloan AP, Ehde DM. Mental health comorbidity in MS. depression, anxiety, and bipolar disorder. Curr Neurol Neurosci Rep. 2016;16:106. 
74. Anisman H, Merali Z, Hayley S. Neurotransmitter, peptide and cytokine processes in relation to depressive disorder: comorbidity between depression and neurodegenerative disorders. Prog Neurobiol. 2008:85:1-74.

75. Hayley S, Anisman H. Multiple mechanisms of cytokine action in neurodegenerative and psychiatric states: neurochemical and molecular substrates. Curr Pharm Des. 2005;11:947-62.

76. Tansey MG, Goldberg MS. Neuroinflammation in Parkinson's disease: its role in neuronal death and implications for therapeutic intervention. Neurobiol Dis. 2010;37:510-8.

77. Yin F, Sancheti H, Patil I, Cadenas E. Energy metabolism and inflammation in brain aging and Alzheimer's disease. Free Radic Biol Med. 2016;100:108-22.

78. Giunti D, Parodi B, Cordano C, Uccelli A, Kerlero DRN. Can we switch microglia's phenotype to foster neuroprotection? Focus on multiple sclerosis. Immunology. 2014;141:328-39.

79. Jones KA, Thomsen C. The role of the innate immune system in psychiatric disorders. Mol Cell Neurosci. 2013;53:52-62.

80. Miller AH, Maletic V, Raison CL. Inflammation and its discontents: the role of cytokines in the pathophysiology of major depression. Biol Psychiatry. 2009;65:732-41.

81. Vollmer-Conna U, Fazou C, Cameron B, Li H, Brennan C, Luck L, Davenport T, Wakefield D, Hickie I, Lloyd A. Production of pro-inflammatory cytokines correlates with the symptoms of acute sickness behaviour in humans. Psychol Med. 2004;34:1289-97.

82. Maes M. The immunoregulatory effects of antidepressants. Hum Psychopharmacol. 2001;16:95-103.

83. Hu W, Zhang Y, Wu W, Yin Y, Huang D, Wang Y, Li W, Li W. Chronic glucocorticoids exposure enhances neurodegeneration in the frontal cortex and hippocampus via NLRP-1 inflammasome activation in male mice. Brain Behav Immun. 2016;52:58-70.

84. Rinwa P, Kumar A. Quercetin suppress microglial neuroinflammatory response and induce antidepressent-like effect in olfactory bulbectomized rats. Neuroscience. 2013;255:86-98.

85. Bollinger $\mathrm{L}$, Bergeon BC, Wellman CL. Differential effects of stress on microglial cell activation in male and female medial prefrontal cortex. Brain Behav Immun. 2016:52:88-97.

86. Diz-Chaves Y, Pernia O, Carrero P, Garcia-Segura LM. Prenatal stress causes alterations in the morphology of microglia and the inflammatory response of the hippocampus of adult female mice. J Neuroinflammation. 2012;9:71.

87. Hinwood M, Morandini J, Day TA, Walker FR. Evidence that microglia mediate the neurobiological effects of chronic psychological stress on the medial prefrontal cortex. Cereb Cortex. 2012;22:1442-54.

88. Iwata M, Ishida H, Kaneko K, Shirayama Y. Learned helplessness activates hippocampal microglia in rats: a potential target for the antidepressant imipramine. Pharmacol Biochem Behav. 2016;150-151:138-46.

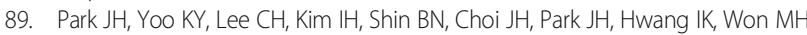
Comparison of glucocorticoid receptor and ionized calcium-binding adapter molecule 1 immunoreactivity in the adult and aged gerbil hippocampus following repeated restraint stress. Neurochem Res. 2011;36:1037-45.

90. Xu L, He D, Bai Y. Microglia-mediated inflammation and neurodegenerative disease. Mol Neurobiol. 2016:53:6709-15.

91. Hong H, Kim BS, Im HI. Pathophysiological role of neuroinflammation in neurodegenerative diseases and psychiatric disorders. Int Neurourol J. 2016;20:S2-7.

92. Weisman GA, Camden JM, Peterson TS, Ajit D, Woods LT, Erb L. P2 receptors for extracellular nucleotides in the central nervous system: role of P2X7 and P2Y (2) receptor interactions in neuroinflammation. Mol Neurobiol. 2012;46:96-113.

93. Latz E, Xiao TS, Stutz A. Activation and regulation of the inflammasomes. Nat Rev Immunol. 2013;13:397-411.

94. Hewinson J, Moore SF, Glover C, Watts AG, MacKenzie AB. A key role for redox signaling in rapid $\mathrm{P} 2 \mathrm{X} 7$ receptor-induced $\mathrm{IL}-1$ beta processing in human monocytes. J Immunol. 2008;180:8410-20.

95. Xu Y, Sheng H, Bao Q, Wang Y, Lu J, Ni X. NLRP3 inflammasome activation mediates estrogen deficiency-induced depression- and anxiety-like behavior and hippocampal inflammation in mice. Brain Behav Immun. 2016:56:175-86.

96. Pan Y, Chen XY, Zhang QY, Kong LD. Microglial NLRP3 inflammasome activation mediates IL-1beta-related inflammation in prefrontal cortex of depressive rats. Brain Behav Immun. 2014;41:90-100.

97. Zhang Y, Liu L, Peng YL, Liu YZ, Wu TY, Shen XL, Zhou JR, Sun DY, Huang AJ, Wang $X$, et al. Involvement of inflammasome activation in lipopolysaccharide-induced mice depressive-like behaviors. CNS Neurosci Ther. 2014;20:119-24.
98. Ma Q, Chen S, Hu Q, Feng H, Zhang JH, Tang J. NLRP3 inflammasome contributes to inflammation after intracerebral hemorrhage. Ann Neurol. 2014;75:209-19.

99. Feng L, Chen Y, Ding R, Fu Z, Yang S, Deng X, Zeng J. P2X7R blockade prevents NLRP3 inflammasome activation and brain injury in a rat model of intracerebral hemorrhage: involvement of peroxynitrite. J Neuroinflammation. 2015;12:190.

\section{Submit your next manuscript to BioMed Central and we will help you at every step:}

- We accept pre-submission inquiries

- Our selector tool helps you to find the most relevant journal

- We provide round the clock customer support

- Convenient online submission

- Thorough peer review

- Inclusion in PubMed and all major indexing services

- Maximum visibility for your research

Submit your manuscript at www.biomedcentral.com/submit

) Biomed Central 